\title{
O APROVEITAMENTO DA ENERGIA SOLAR E AS RELAÇÕES COM A EDUCAÇÃO AMBIENTAL EM DOIS ESTUDOS DE CASO NO PARANÁ
}

\author{
Ricardo Colatusso ${ }^{1}$ \\ Carlos Coimbra Araújo² \\ Eduardo Felga Gobbi ${ }^{3}$ \\ Fabiana Andreoli ${ }^{4}$
}

Resumo: Este artigo apresenta aspectos do aproveitamento da energia e suas relações com a educação ambiental utilizando a abordagem da percepção socioambiental de moradores de algumas localidades da área urbana de Curitiba, Paraná, Brasil. A pesquisa consiste em uma abordagem quantitativa e qualitativa que buscou compreender o uso de sistemas de aquecimento solar e geração fotovoltaica nos hábitos e costumes da população usuária e possíveis mudanças comportamentais decorrentes da presença dessa nova tecnologia. Os fatores que influenciaram a abordagem: (a) o conhecimento prévio desse complexo habitacional pelo pesquisador; (b) a delimitação espacial do complexo habitacional com um número relativamente alto de aquecedores solares ou painéis fotovoltaicos, o que facilitou a operacionalização da pesquisa; (c) a falta de banco de dados sobre os proprietários de sistemas de aquecimento solar / fotovoltaico. A pesquisa revelou que há um grande déficit, espaço e oportunidade de trabalhar a educação ambiental nesse tipo de população.

Palavras-chave: Energia Solar; Educação Ambiental; Sustentabilidade; Desenvolvimento.

\footnotetext{
1 Universidade Federal do Paraná. E-mail: ricardo.colatusso13@gmail.com

2 Universidade Federal do Paraná. E-mail: carlos.coimbra@ufpr.br

3 Universidade Federal do Paraná. E-mail: eduardo.felga@gmail.com

${ }^{4}$ Pontifícia Universidade Católica do Paraná. E-mail: fabiana.andreoli@pucpr.br
} 
Abstract: This article presents aspects of the use of energy and its relationship with environmental education, using the approach of socio-environmental perception of residents of some locations in the urban area of Curitiba, Paraná, Brazil. A research consists of a quantitative and qualitative approach that seeks to understand the use of solar heating systems and photovoltaic generation in habits and costumes of the user population and possible behavioral changes used by the presence of this new technology. The factors that influence the approach: (a) the researcher's prior knowledge of this housing complex; (b) a spatial definition of the housing complex with a relatively high number of solar heaters or photovoltaic panels, or that facilitates the operationalization of the research; (c) lack of database on solar / photovoltaic heating systems. A survey revealed that there is a large deficit, space and opportunity to work on environmental education in this type of population.

Keywords: Solar Energy; Environmental Education; Sustainability; Development.

\section{Introdução}

Vários pensadores, a partir do século XIX, iniciaram estudos relacionando a sociedade e o uso da energia. Fred Cottrell, em sua obra, trata principalmente das mudanças culturais baseadas na energia que ocorreram na Europa e na América do Norte analisando as culturas camponesas subdesenvolvidas. A tese do livro é: "a energia disponível ao homem limita o que pode fazer e influencia o que fará" (COTTRELL, 1955). Esta obra se foca em fatores como o desenvolvimento cultural a partir da dependência de fontes de energia de baixo rendimento, como plantas e animais, à dependência de fontes de alto rendimento, como os combustíveis fósseis. As consequências econômicas, sociais e políticas das mudanças tecnológicas dos últimos séculos são analisadas em detalhes, bem como a organização da produção, sobre a distribuição e sobre a utilização de energia eólica, hídrica, elétrica e de combustíveis fósseis. Assim, segundo o autor, existe não um determinismo, mas uma relação entre o desenvolvimento da sociedade e o aumento do uso da energia.

Em seu livro "A energia e a evolução da cultura" Leslie White é conhecido por sua visão evolutiva da cultura e a explicação deste fenômeno a partir da energia, tendo esta um papel chave. Inicialmente descreve que o ser humano necessita de energia, razão pela qual vai explorar a primeira coisa que está ao seu alcance. Sendo recursos de baixa energia, as primeiras sociedades não tiveram alterações significativas em sua organização. Quando começa a ocorrer a exploração de energia há uma mudança cultural evolutiva. Há um crescimento do consumo de energia per capita, e assim vem a revolução agrícola. A segunda grande fase de desenvolvimento cultural foi a descoberta da "nova energia", carvão, gás natural e petróleo. Então, consequentemente, houve um efeito similar ao anterior, houve mais energia para o desenvolvimento cultural com incremento da engenharia, arte etc. (WHITE, 1959). 
Um aspecto que deve ser ressaltado é que o desenvolvimento das sociedades e 0 atendimento as suas necessidades só foram possíveis com a utilização de energia. Esse uso cada vez mais crescente e dependente dos recursos energéticos transformou esses em trunfos de poder, considerando a disposição em qualidade e quantidade nos diversos territórios. Assim, a energia é uma das principais questões de qualquer país para proporcionar qualidade de vida à sua população. Os Estados estão sempre preocupados em instalar medidas que possam afastar da sociedade o risco da falta de energia ou para diminuir a sua instabilidade. Com a Revolução industrial, os recursos energéticos tornaram-se centrais nas atividades produtivas.

A energia, portanto, tem uma característica relevante nas sociedades em função da sua altíssima relação com a economia, além da tecnologia e do meio ambiente. Assim, se um determinado país não permanecer sob uma condição de segurança energética, por conseguinte, seu risco de sobrevivência será alto. Nesse sentido, o estabelecimento de estratégias para 0 atendimento da demanda de energia de uma sociedade é sempre fundamental para a estabilidade desses países e sociedades.

O Brasil possui grande potencial para a utilização das energias renováveis, em especial a energia solar, em suas diversas formas de aproveitamento. A irradiação solar média incidente sobre o território brasileiro apresenta valores maiores que muitos países europeus, onde a utilização da energia solar já é bastante difundida.

Também, há percepções de que a economia de mercado, por si só, não é capaz de atender às populações menos favorecidas, no que diz respeito à oferta de energia, sem que haja um modelo de desenvolvimento local que atenda essas carências. Assim, o acesso a fontes renováveis de energia, com custos razoáveis e compatíveis com a renda média da população brasileira, pode contribuir como fator decisivo para o desenvolvimento humano local e a justiça ambiental.

Assim, os projetos de desenvolvimento local com utilização de energias renováveis podem ser uma solução paralela para os problemas de infraestrutura energética e melhoria no acesso a este recurso; podem, ainda, trazer a melhoria da distribuição de renda, uma vez que diminuirão a dependência de energia fornecida pelas concessionárias; e podem ser um programa estratégico, se planejado a médio e longo prazo como benefício à população.

Neste trabalho se propõe verificar a percepção ambiental dos moradores que utilizam tecnologias de aproveitamento solar em suas residências. A pesquisa de campo, por meio de dois estudos de caso, buscou avaliar que influências a instalação de sistemas de aquecimento solar e de microgeração de energia solar fotovoltaica exercem na percepção ambiental dos moradores dessas instalações. 


\section{Educação Ambiental}

$\mathrm{Na}$ visão de Edgar Morin (1997), neste milênio, todos os cidadãos precisarão identificar e entender o contexto, os entornos e os contornos (o Global, o Multidimensional e o Complexo), articulando as informações. Principalmente com seu método Morin, propõe uma ferramenta de análise efetiva, integrando diferentes aspectos da problemática ambiental, às vezes conflitantes, porém complementares.

No Brasil, Floriani e Knechtel (2003), trazem algumas referências epistemológicas básicas e reflexões sobre as condições constitutivas e possibilidades de acesso ao conhecimento que permeiam as práticas socioeducativas, inseridas na interface dos problemas socioambientais.

Para se conhecer a dinâmica dos processos socioambientais é necessário um conhecimento científico que vai muito além do conhecimento disciplinar. Como destacado por Enrique Leff (1998), o saber ambiental descobre as ciências ambientais constituídas por um conjunto de especializações que incorporam enfoques ecológicos às disciplinas tradicionais e se estende, mais além do campo de articulação das ciências, para o terreno dos valores éticos, dos conhecimentos práticos e dos saberes tradicionais. $O$ "saber ambiental" parte do conhecimento de múltiplas disciplinas integradas, para construir um campo teórico e prático orientado para as interações sociedade-natureza (LEFF, 1998).

Necessário se faz, portanto, elaborar novos referenciais para as práticas interdisciplinares entre natureza e sociedade. Essa nova maneira de pensar e construir o conhecimento exige uma nova "pedagogia do conhecimento", ou seja, questionar permanentemente sobre como fazer a interdisciplinaridade e os resultados desse fazer, em um processo realimentado e intermediado pela educação, incluída aí a educação ambiental.

Assim, a necessária interação entre as disciplinas somente terá sentido e fará efeito com a prática social educativa e a consequente aplicação na realidade social. Resumindo, a dimensão social exige transpor a ciência e as atividades acadêmicas no que diz respeito às temáticas do meio ambiente e do desenvolvimento.

De outro lado, a segurança e a eficiência energética devem ser preocupação de todos os países. Sem um acesso seguro à energia contínua e eficiente, é impossível o desenvolvimento com sustentabilidade, elemento fundamental para também conseguir o bem estar social da população (educação, saúde transporte, segurança, entre outros).

Estudos como os realizados pela OLADE (Organizacion Latinoamericana para El Desarrollo) mostram que cidadãos informados e sensibilizados para a necessidade de usar a energia de forma racional e eficiente, tendem a economizar $10 \%$ a $15 \%$, quando comparados àqueles que não estão atentos para esta questão. A utilização de tecnologias mais 
eficientes e a utilização energética mais racional e inteligente são duas frentes que devem ser consideradas na formulação de políticas.

A obtenção de economia de energia exige, por um lado, o desenvolvimento de técnicas, produtos e serviços eficientes do ponto de vista energético e, por outro, uma alteração dos padrões comportamentais, com vista a um menor consumo de energia sem perda de qualidade de vida. Esse desafio exige, também, a capacitação de profissionais que possam promover o debate ambiental e a elaboração, implantação e desenvolvimento de projetos que promovam a educação para a sustentabilidade. Essa tarefa pode ser facilitada na medida em que cidadãos que têm o compromisso de proteger a natureza e o planeta reconheçam o papel central da educação na formação de valores e na ação social.

Considerando que a educação ambiental é um processo dinâmico e em permanente construção, um instrumento capaz de contribuir, com esse papel educativo, seria o de desenvolver a percepção dos cidadãos sobre os meios para a racionalização do uso da energia e a melhoria da eficiência energética. Em termos pedagógicos, cabe à educação ambiental concorrer à formação e exercício da cidadania, possibilitando aos participantes desse processo a compreensão necessária dos conhecimentos sobre as causas e consequências dos problemas socioambientais, pela reflexão e ações no sentido da melhoria de vida.

Do ponto de vista do cidadão que recebe a nova tecnologia, utiliza-se o conceito da percepção humana, que é interpretada como um indicador básico para 0 atingimento dos diversos níveis de conscientização ambiental. A interação do conhecimento popular e acadêmico normalmente apresenta grande potencial para que se atinja um efetivo cuidado com o meio ambiente. A interpretação ambiental gerada pela percepção pode ser considerada um fator importante no nível de consciência das populações e comunidades não acadêmicas que utilizam as energias renováveis.

Os estudos que utilizam a percepção ambiental pretendem investigar a forma como o ser humano enxerga, interpreta, convive e se adapta à realidade do meio em que vive, principalmente em se tratando de ambientes instáveis ou vulneráveis socialmente e naturalmente (OKAMOTO, 1996).

Ampliando para o raciocínio da percepção ambiental, define-se como a maneira como os seres humanos organizam e interpretam suas impressões sensoriais, a fim de dar sentido ao seu ambiente (ROBBINS, 1999). A percepção indica, ainda, uma "função de captação de informação dos acontecimentos do meio exterior, ou do meio interno, pela via dos mecanismos sensoriais" (DORON; PAROT, 2001).

Diversas são as formas de se estudar a percepção ambiental, como por exemplo: questionários, mapas de contorno, representação fotográfica, entre outros. Existem alguns trabalhos em percepção ambiental que buscam não apenas o entendimento daquilo que a população pesquisada percebe, mas 
também, promover a sensibilização, bem como o desenvolvimento da compreensão do ambiente (FAGGIONATO, 2011).

De maneira prática, por meio da percepção e interpretação ambientais, a população pode atribuir valores e importâncias em sua moradia, bem como, para a área em seu entorno. Sendo assim um processo valioso que desperta a sensibilização do ser humano em relação às realidades ambientais, é fundamental a contribuição e mediação da educação ambiental como resultado final desse processo.

Então, a Educação Ambiental como meio intermediário de percepção do conhecimento dos valores e ações que os seres humanos possuem frente ao meio ambiente, poderá elaborar propostas e práticas socioeducativas que venham a atender aos usuários das tecnologias para energias renováveis, visando provocar respostas mais efetiva que contribuam para a sustentabilidade socioambiental.

Com base no que foi colocado nos parágrafos anteriores, considera-se que a percepção ambiental pode ser utilizada para avaliar a problemática em torno das questões das energias renováveis, especialmente a energia solar e das suas diversas correlações. Emergiu, dessa forma, a necessidade de investigar, através de questionário, qual a percepção ambiental dos diferentes usuários de tecnologias para energia solar dentro dos limites dessa pesquisa.

\section{Metodologia}

A realização do presente estudo compreendeu investigar as relações entre o aproveitamento da energia solar e educação ambiental verificando a percepção ambiental despertada na população pela utilização desses sistemas.

Essa pesquisa consiste em uma abordagem quantitativa e qualitativa, que buscou o entendimento da utilização de sistemas de energia solar de aquecimento e de geração fotovoltaica aos hábitos e costumes da população usuária e possíveis mudanças de comportamentos decorrentes da presença dessa nova tecnologia no espaço habitacional. Configura-se como estudo de caso, pertinente à zona urbana de Curitiba. Utilizou-se a pesquisa descritiva, pois buscou o entendimento aprofundado do objeto de estudo; sendo também uma pesquisa exploratória, pois incluiu o levantamento de dados em campo, e analítica, já que dos dados analisados, extraiu-se sua relevância (GIL, 1999).

Como o território paranaense é composto por diversas regiões, não seria possível testar uma hipótese geral analisando todas estas diferenças ambientais e culturais existentes. Para isso, optou-se por realizar a pesquisa utilizando estudos de caso. Os estudos de caso estão baseados em uma metodologia cujas informações são levantadas por meio de uma amostra reduzida, o que em si não possibilita demonstrar o universo de cada situação, mas permite ilustrar uma situação concreta. Segundo o autor Robert Yin, os estudos de casos envolvem uma análise intensiva de um número relativamente 
pequeno de situações que às vezes se resumem a um único caso. A adoção de múltiplos casos é desejável quando a intenção da pesquisa é a descrição de um fenômeno, a construção de teoria ou o teste de teoria (YIN, 1990).

Os estudos de caso permitem explorar situações da vida real, cujos limites não estão claramente definidos, e ainda explicar variáveis de determinados fenômenos que não possibilitam a utilização de levantamentos ou experimentos (GIL, 1999).

A entrevista foi utilizada como uma técnica de pesquisa onde o pesquisador formula questões ao entrevistado e este as responde. A entrevista semiestruturada foi a técnica de interrogação utilizada neste estudo; o entrevistador explorou pontos de maior interesse no decorrer do processo, não se limitando somente a uma relação fixa de perguntas. (GIL, 1999). Daí a necessidade da pesquisa qualitativa também estar integrada.

Para efetivação das entrevistas foram construídos dois instrumentos de pesquisa de campo. Um a ser aplicado nos usuários de sistemas de aquecimento solar e outro em usuários de sistemas de geração de energia solar fotovoltaica.

Após a coleta de dados, foi feita a análise dos dados quantitativos e o cruzamento desses com os dados qualitativos; com os quais foi realizada a análise de conteúdo - discussão e elaboração da síntese (BARDIN, 2009).

Por fim, a pesquisa ainda é caracterizada como ex-post facto, ou seja, realizada após a implantação das tecnologias de aquecimento solar ou de microgeração fotovoltaica nas residências (GIL, 1999).

\section{Estudo de caso para aquecimento solar}

Para compor este estudo de caso, foi escolhido o conjunto habitacional denominado de Moradias Nilo, estabelecido na cidade de Curitiba / PR, no bairro Alto Boqueirão. Nesta localidade foram implantadas 66 unidades habitacionais do Programa Minha Casa Minha Vida em parceria com a COHAB - Companhia de Habitação Popular de Curitiba. O conjunto habitacional foi destinado para famílias que estavam em situação de risco na Vila Nova, uma ocupação irregular localizada ao lado do atual conjunto. São famílias que viviam em condições precárias e num local impróprio para moradia (Figura 1).

Os fatores que influenciaram na escolha dessas residências foram: (a) o conhecimento prévio deste conjunto habitacional pelo autor da pesquisa; (b) a delimitação espacial do conjunto habitacional com uma quantidade relativamente grade de aquecedores solares, 0 que facilitou a operacionalização da pesquisa; (c) a inexistência de base de dados sobre proprietários de sistemas de aquecimento solar.

O estudo compreendeu uma avaliação pós ocupacional a fim de se observar que influências a instalação de sistemas de aquecimento solar exerce 
no consumo de energia elétrica de residências que utilizam essas tecnologias, bem como verificar a percepção ambiental dos moradores dessas instalações.

Nessas unidades habitacionais foi aplicado um questionário em 40 residências, a fim de entender se o sistema está adequado ao uso dessa população. Além disso, observar qual a percepção ambiental e se houve algum tipo de formação ambiental para essa população. Com abordagem sobre quatro aspectos - social, cultural, econômico e ambiental - tem-se um quadro geral do ponto de vista dos moradores sobre a incorporação do sistema de aquecimento solar de água em suas residências. Os dados referentes ao estudo de caso foram coletados entre os meses de setembro e outrubro de 2017, por meio de visitas às residências do conjunto habitacional para aplicação dos questionários e observações em campo. Após a aplicação dos questionários foram iniciadas as tabulações e as análises dos dados.

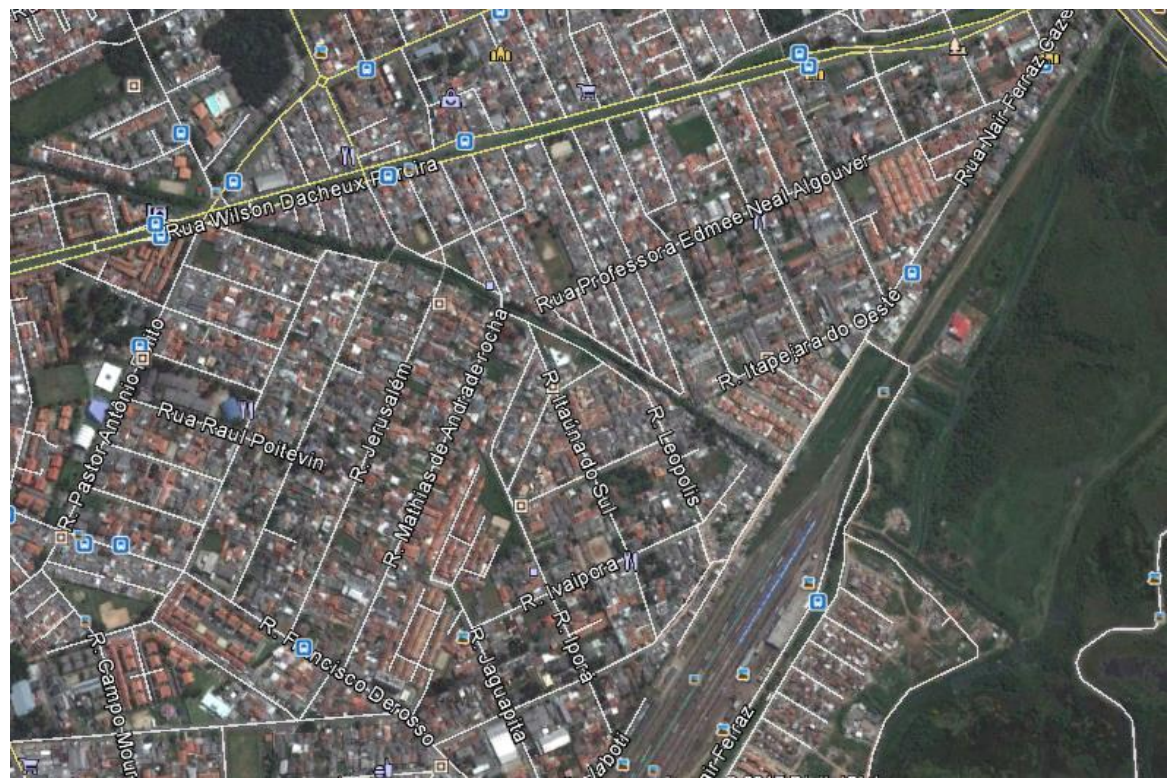

Figura 1: Vista aérea do Conjunto Moradias Nilo.

Fonte: Google Maps (2017).

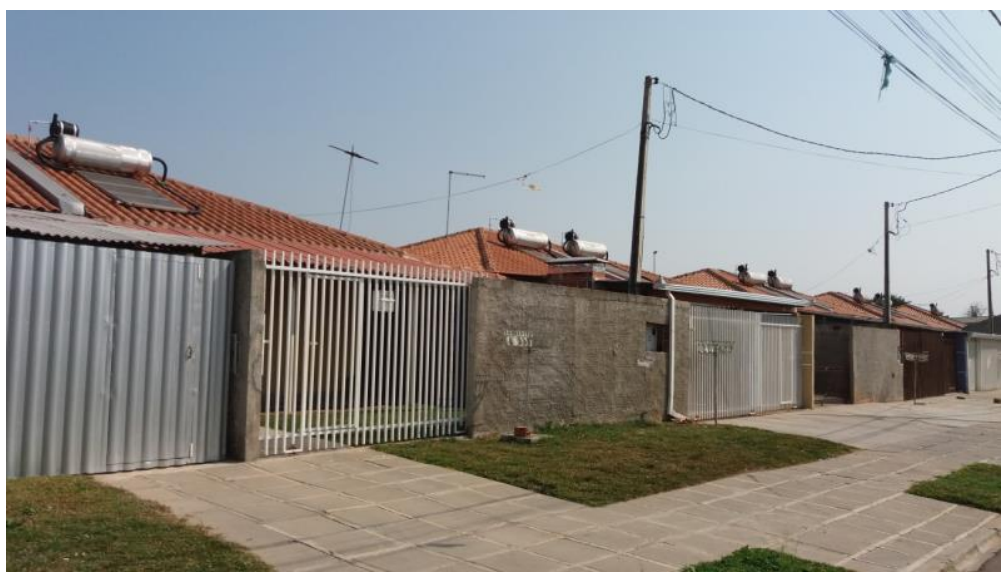

Figura 2: Moradias Nilo - Alto Boqueirão - CTBA/PR.

Fonte: Autores (2017). 
Conforme ilustrado na Tabela $1,55,0 \%$ dos questionários foram respondidos por mulheres e $45,0 \%$ por homens. Nestas respostas, $17,5 \%$ estão morando há dois anos nessa residência, enquanto 65,0\% estão morando há dois anos e meio e $17,5 \%$ há três anos. Com relação à renda familiar, $25,0 \%$ das famílias recebem até um salário-mínimo vigente no Brasil, 70,0\% das famílias percebem de um a três salários-mínimos e apenas $5 \%$ recebem mais de três salários mínimos. Observando a escolaridade dessa população respondente, verifica-se que $0 \%$ é analfabeto, $37,5 \%$ tem o ensino fundamental I, antiga $4^{a}$. série, $47,5 \%$ tem o ensino fundamental completo, apenas $15 \%$ tem o ensino médio completo e $0 \%$ tem formação superior. Ainda observando aspectos socioeconômicos, com relação ao número de pessoas moradoras em cada habitação, $0 \%$ tem apenas um habitante, $7,0 \%$ tem duas pessoas em cada habitação, $46,5 \%$ tem três habitantes, $32,6 \%$ do universo pesquisado contemplam quatro moradores em cada habitação e apenas 13,9\% com cinco moradores em cada casa. Não se constatou casos de seis ou mais moradores em uma única habitação.

Tabela 1: Caracterização socioeconômica da população entrevistada para aquecimento solar.

\begin{tabular}{|c|c|c|c|}
\hline CATEGORIA & SUBCATEGORIA & FREQ. ABSOLUTA & $\%$ \\
\hline 1) Gênero & $\begin{array}{c}\text { Masculino } \\
\text { Feminino } \\
\text { Total }\end{array}$ & $\begin{array}{l}22 \\
18 \\
40\end{array}$ & $\begin{array}{c}55,00 \% \\
45,00 \% \\
100,00 \%\end{array}$ \\
\hline 2) Tempo de Moradia & $\begin{array}{c}2,0 \text { anos } \\
2,5 \text { anos } \\
3,0 \text { anos } \\
\text { Total }\end{array}$ & $\begin{array}{c}7 \\
26 \\
7 \\
40\end{array}$ & $\begin{array}{c}17,50 \% \\
65,00 \% \\
17,50 \% \\
100,00 \%\end{array}$ \\
\hline 3) Renda Familiar & $\begin{array}{c}\text { até } 1 \text { S.M. } \\
1 \text { a } 3 \text { S.M. } \\
\text { Mais de } 3 \text { S.M. } \\
\text { Total }\end{array}$ & $\begin{array}{c}10 \\
28 \\
2 \\
40\end{array}$ & $\begin{array}{c}25,00 \% \\
70,00 \% \\
5,00 \% \\
100,00 \%\end{array}$ \\
\hline 4) Escolaridade & $\begin{array}{c}\text { Analfabeto } \\
\text { até 4a. Série } \\
\text { Ensino Fundamental } \\
\text { Ensino Médio } \\
\text { 3o. Grau } \\
\text { Total }\end{array}$ & $\begin{array}{c}0 \\
15 \\
19 \\
6 \\
0 \\
40\end{array}$ & $\begin{array}{c}0,00 \% \\
37,50 \% \\
47,50 \% \\
15,00 \% \\
0,00 \% \\
100,00 \%\end{array}$ \\
\hline 5) $N^{\circ}$. pessoas na hab. & $\begin{array}{c}\text { Uma } \\
\text { Duas } \\
\text { Três } \\
\text { Quatro } \\
\text { Cinco } \\
\text { Seis } \\
\text { Total }\end{array}$ & $\begin{array}{c}0 \\
3 \\
20 \\
14 \\
6 \\
0 \\
43\end{array}$ & $\begin{array}{c}0,00 \% \\
6,98 \% \\
46,51 \% \\
32,56 \% \\
13,95 \% \\
0,00 \% \\
100,00 \%\end{array}$ \\
\hline
\end{tabular}

Fonte: Resultados da Pesquisa 
Finalizando a caracterização socioeconômica, conforme ilustra a Figura 3, há uma grande distribuição de tipos de ocupação do chefe dessas famílias, especialmente por se tratar de área urbana. Destaques especiais para 15,0\% que figuraram como empregados domésticos, $10,0 \%$ de pedreiros e $7,5 \%$ de aposentados. Outro detalhe, nesta população se apresentou $10,0 \%$ de desempregados, refletindo a situação econômica atual do país.

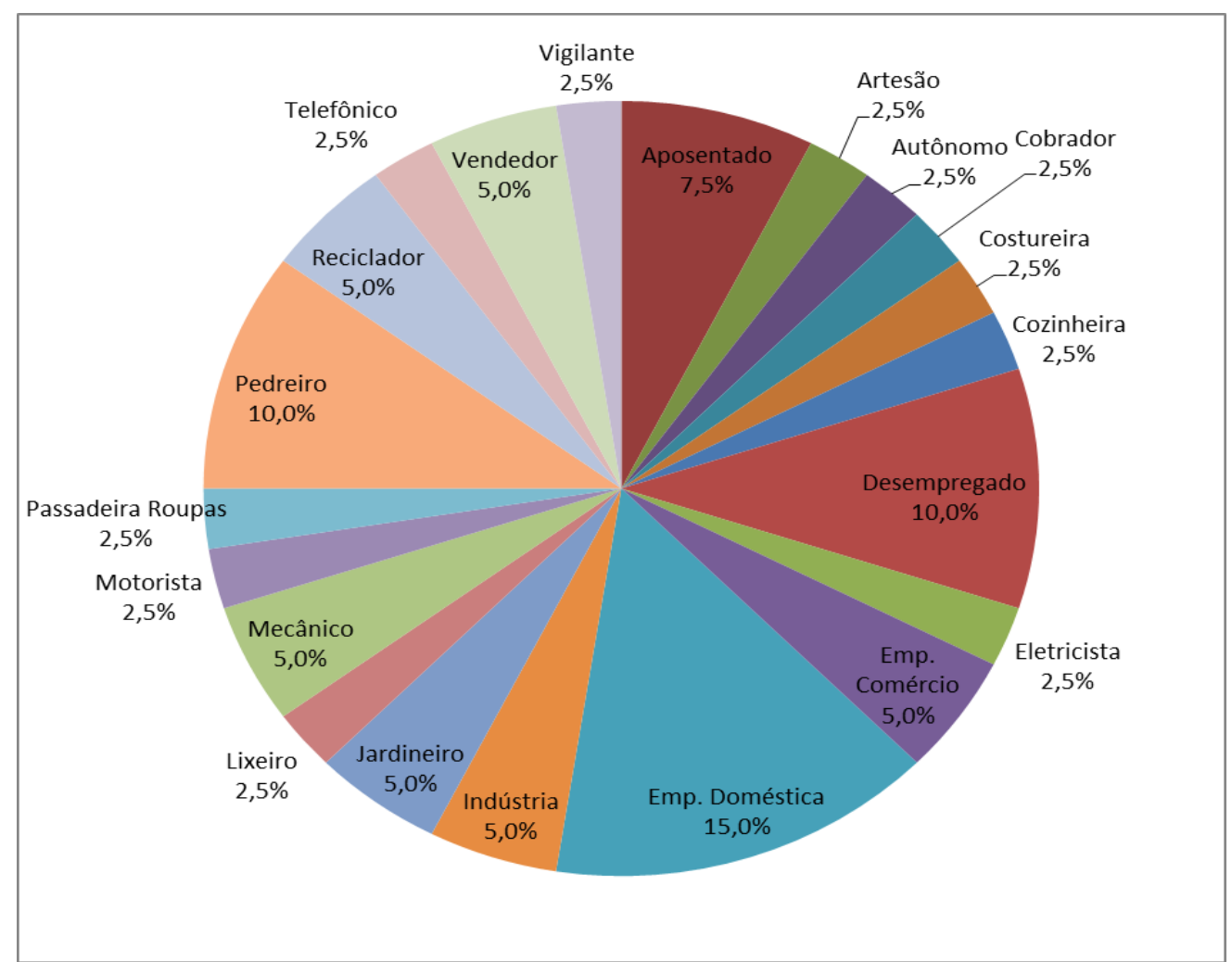

Figura 3: Ocupação do chefe da família - Moradias Nilo Fonte: Autores (2017).

Quanto à adaptação ao uso do aquecimento solar, como se trata de aspectos de incorporação de tecnologia, foi proposto verificar se os respondentes sabem utilizar o equipamento. Em $100 \%$ dos casos, as respostas foram que sim, pois a construtora fez esse treinamento no momento de entrega das residências.

Foi questionado se o equipamento funciona bem. Em $100 \%$ dos casos a resposta foi que sim. Em uma única resposta, houve certo desconforto, citando que a água esquenta demasiadamente.

Também neste tópico, foi questionado se na moradia anterior havia chuveiro: em $100 \%$ dos casos a resposta foi sim e do tipo elétrico. Quando perguntado sobre qual era mais confortável, todos apontaram como sendo que o aquecedor solar, pois permite um banho mais agradável. 
No último tópico da pesquisa de campo a intenção é traçar considerações sobre a percepção ambiental da população pesquisada. Quando perguntado se foi explicado por que instalaram o aquecimento solar, $100 \%$ dos casos foram respondidos como sim, para economia de energia. Verifica-se, então, que nesses casos de habitações de interesse social, a explicação dada à população que recebeu essa tecnologia foi exclusivamente a economia financeira. Há aqui, uma oportunidade para a educação ambiental nessas comunidades, quando da entrega das casas.

$\mathrm{Na}$ pergunta seguinte quando indagados se consideram o aquecimento solar importante para o meio ambiente, $52,50 \%$ responderam que sim. Embora alguns não saibam explicar. Algumas respostas foram coerentes, como as desses moradores:

"Sim, porque o melhor uso da energia é bom para o meio ambiente."

"Sim, porque diminui a poluição".

"Sim, porque economiza a água das usinas."

Quanto aos que responderam não, simplesmente não entendem a relação entre energia e meio ambiente. Um caso específico mostra o desconhecimento de como é gerada a energia elétrica no Brasil:

"Nossa energia vem só de Itaipú."

Para a pergunta: "Para você, qual a importância do Meio Ambiente?", os resultados encontrados foram: Tudo que envolve a natureza $20,0 \%$, tudo que representa a vida, $27,5 \%$, tudo relacionado ao futuro $25,0 \%$, meio ao qual estamos inseridos $17,5 \%$ e outros $10,0 \%$, conforme ilustrado na Figura 4.

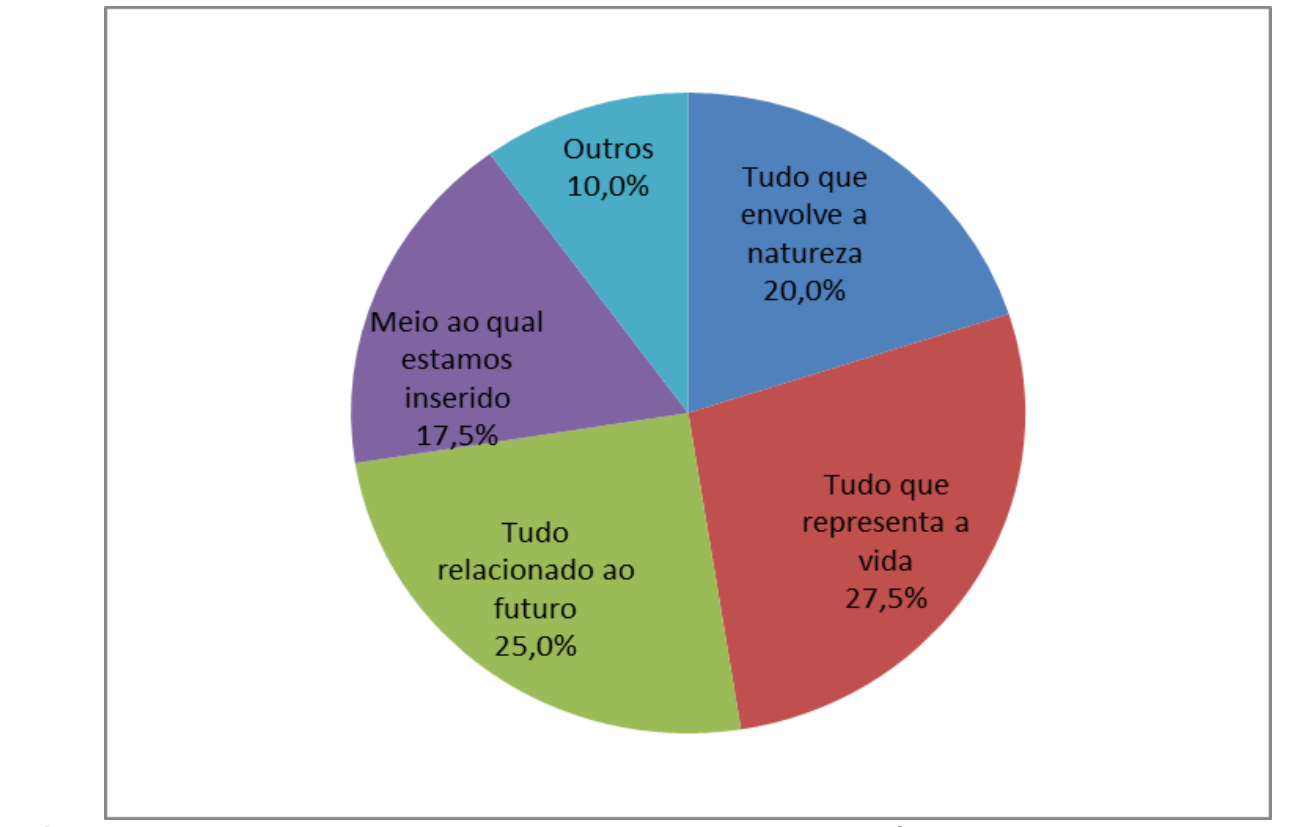

Figura 4: Distribuição das respostas sobre qual a importância do meio ambiente - AS.

Fonte: Autores (2017). 
Fato relevante, como mostrado anteriormente, há nesta pesquisa, 5,0\% de recicladores de lixo. Essa população mostrou, pelas respostas, uma consciência ambiental maior do que pessoas que trabalham em outras atividades. Adicionalmente quando indagados onde aprendeu a importância do meio ambiente, a distribuição das respostas foi conforme ilustrado na Figura 5. Observa-se que $32,5 \%$ disseram que aprenderam esses conceitos na escola, 30,0\% responderam que aprenderam nos meios de comunicação, especialmente televisão, e $22,5 \%$ indicaram que foram motivados pelas empresas onde trabalharam.

Neste item, verifica-se claramente que aqueles respondentes que tiveram algum tipo de formação (ou informação), seja ela na escola, no trabalho ou através de outros meios, conseguem entender melhor a importância do meio ambiente. Em seguida foram questionados quanto às vantagens do aquecimento solar e a grande maioria respondeu na seguinte sequência: primeiramente a financeira, depois o conforto e por último a ambiental. Depois, em uma questão aberta, foi perguntado o que a pessoa gostaria de acrescentar, ainda, sobre o aquecimento solar fazendo parte do cotidiano de sua família. As respostas foram ilustradas na Figura 6: tudo com cuidar do meio ambiente $-5,0 \%$, muito bom (apenas) $-32,5 \%$, tudo com economia de energia $-12,5 \%$, todas as casas deveriam ter $-10,0 \%$, não gostou $-5,0 \%$, nada $12,5 \%$, outras respostas diversas $-22,5 \%$.

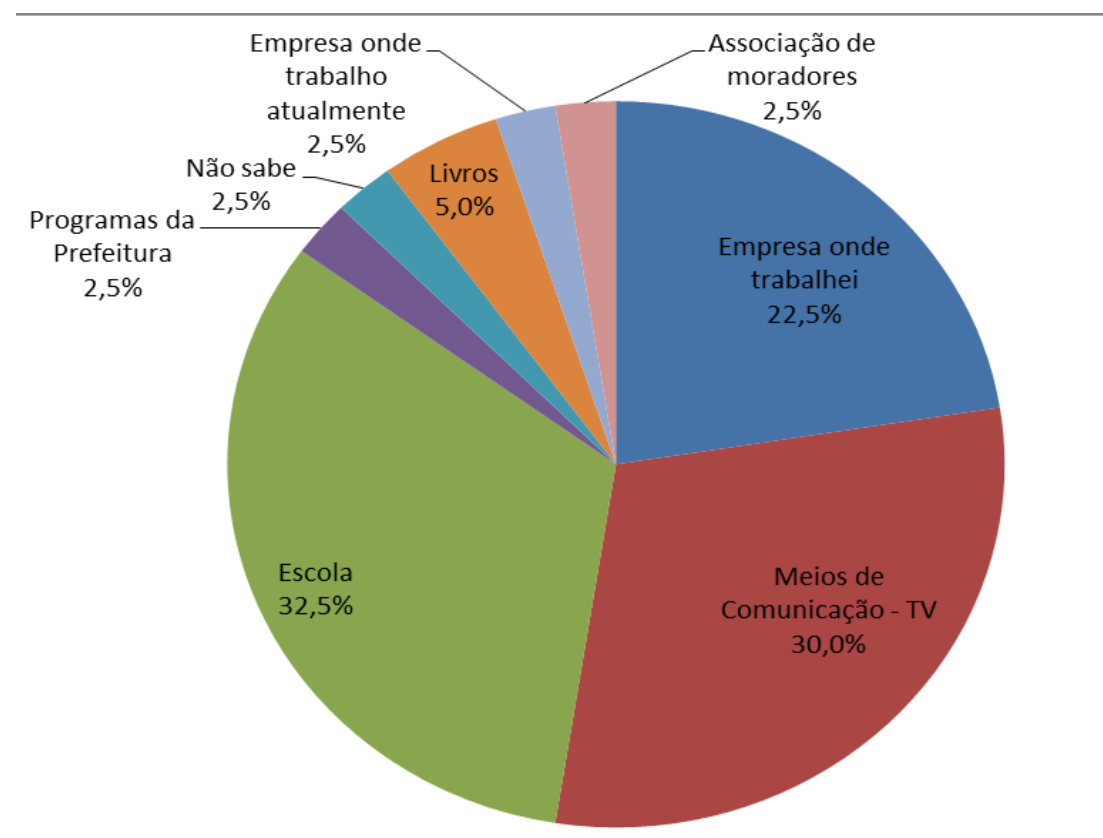

Figura 5: Distribuição das respostas sobre onde aprendeu a importância do Meio Ambiente - AS Fonte: Autores (2017). 


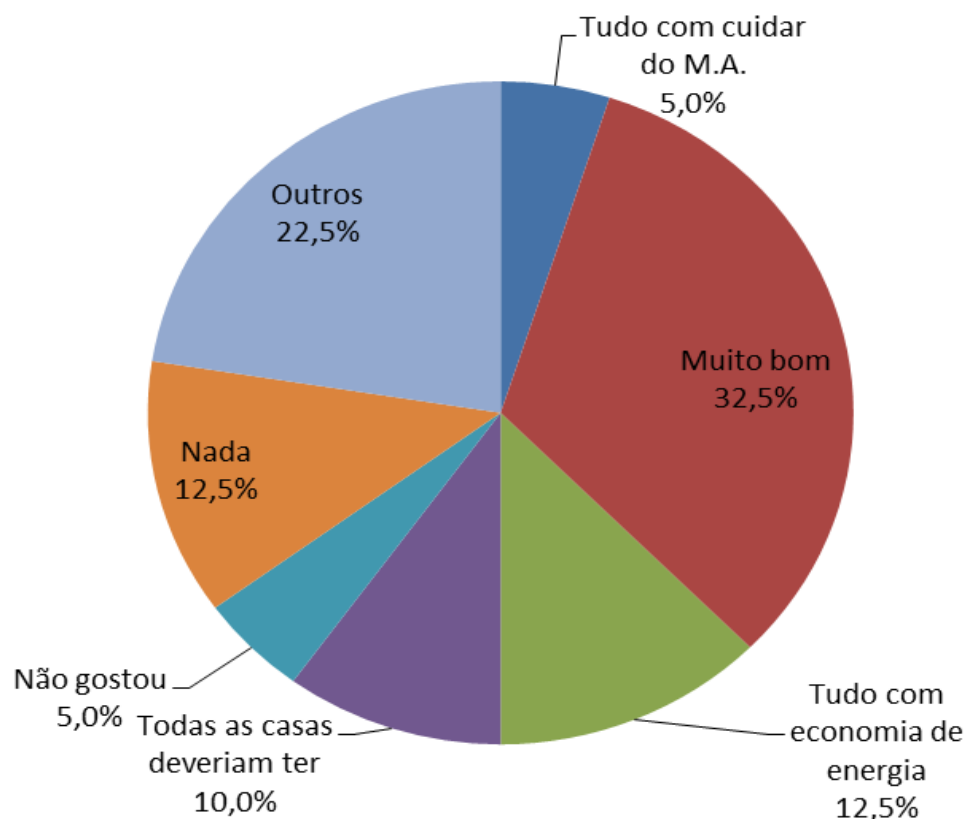

Figura 6: Distribuição das respostas para o que gostaria de acrescentar sobre o as Fonte: Autores (2017).

Em um caso, nesta pergunta, o respondente comentou que seria interessante se a água aquecida chegasse, também, na torneira da cozinha. Por fim foi questionado se o conhecimento que eles têm sobre meio ambiente contribuiu para o entendimento do uso adequado do aquecimento solar. Das respostas levantadas, $57,5 \%$ responderam sim, enquanto $42,5 \%$ responderam não.

\section{Estudo de caso para microgeração de energia solar foltovoltaica}

Essa pesquisa foi realizada na cidade de Curitiba / PR (Figura 7), em diversos bairros da cidade, onde foram instalados sistemas de microgeração de energia solar fotovoltaica por opção do proprietário do imóvel e financiada com recursos próprios. Segundo a ANEEL - Agência Nacional de Energia Elétrica, em Curitiba existiam, no momento da pesquisa, 203 sistemas de microgeração solares fotovoltaicos instalados. 


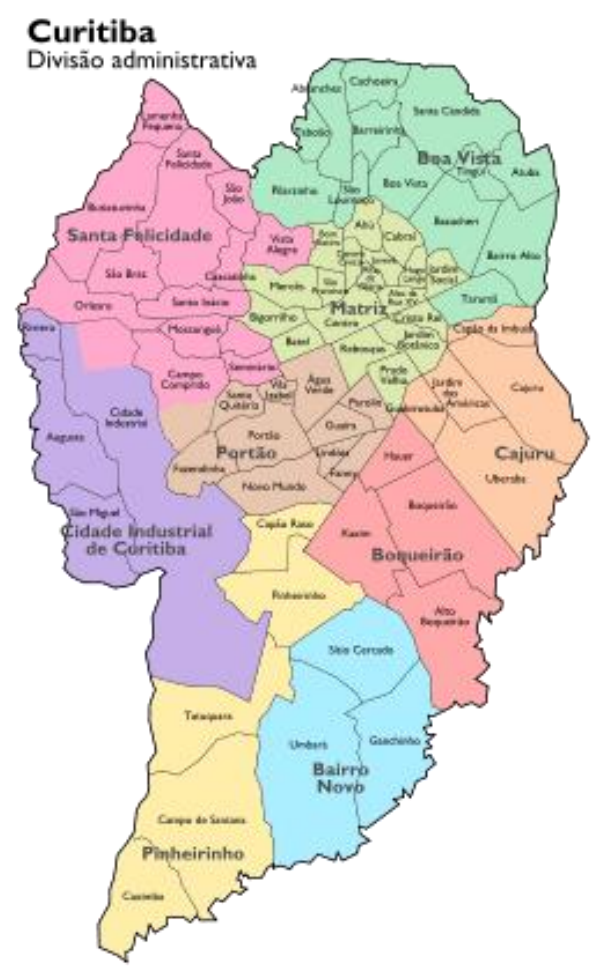

Figura 7: Mapa de Curitiba / PR

Fonte: Prefeitura Municipal de Curitiba

Foram contactadas algumas empresas instaladoras de sistemas de geração de energia fotovoltaica, e duas delas gentilmente cederam suas bases de clientes para que se fizessem as entrevistas. Os fatores que influenciaram na escolha dessas residências foram: (a) o conhecimento prévio destes usuários, pelo autor da pesquisa, uma vez que as empresas cederam suas bases de clientes; (b) delimitação espacial da cidade de Curitiba, o que facilitou a operacionalização da pesquisa. Da mesma forma que no caso dos aquecedores solares, o estudo compreendeu uma avaliação pós ocupacional a fim de se observar que influências a instalação de sistemas de geração de energia solar fotovoltaica exerce no consumo de energia elétrica de residências que utilizam essas tecnologias, bem como verificar a percepção ambiental dos moradores dessas instalações.

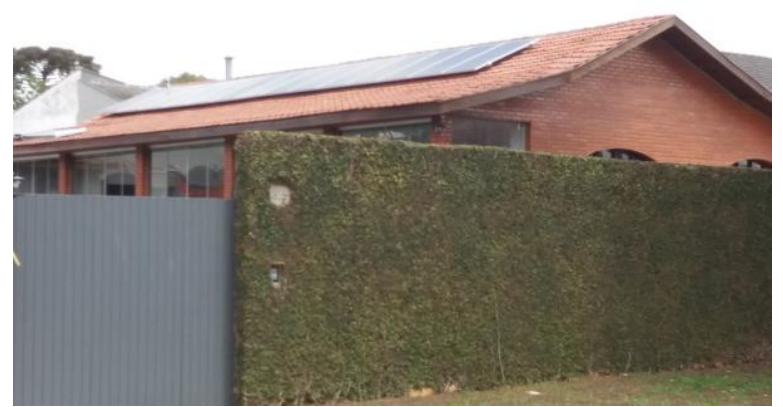

Figura 8: Residência pesquisada com sistema F.V. Fonte: Autores (2017). 
De posse da base de dados cedida, foi aplicado um questionário em 30 residências, a fim de entender as condições após a implantação da tecnologia. Ainda, verificar se a implantação do sistema de geração de energia solar fotovoltaica está adequada ao uso dessa população. Além disso, observar qual a percepção ambiental e se houve algum tipo de formação ambiental a essa população. Com uma abordagem sobre quatro aspectos - social, cultural, econômico e, obtêm-se um quadro geral do ponto de vista dos moradores sobre a incorporação do sistema de geração de energia solar fotovoltaica em suas residências. Os dados referentes ao estudo de caso foram coletados entre os meses de outubro e novembro de 2017, por meio de telefonemas e visitas às residências para aplicação dos questionários e observações em campo. Após a aplicação dos questionários foram iniciadas as tabulações e as análises dos dados.

Os resultados da investigação realizada em campo e aborda os seguintes tópicos: caracterização socioeconômica da população investigada; adequação quanto ao uso do microgerador de energia solar fotovoltaica; economia de energia e financeira e percepção ambiental. Conforme apresentado na metodologia, todos estes tópicos foram levantados por meio de entrevistas estruturadas. Conforme ilustrado na Tabela 2 (próxima página), a seguir, $86,7 \%$ dos questionários foram respondidos por homens e apenas $13,3 \%$ por mulheres. Nestas respostas, $30,0 \%$ estão morando há menos de um ano nessa residência, enquanto $13,3 \%$ estão residindo entre um e dois anos. Já, entre dois e cinco anos de residência são $30,00 \%$ e residindo há mais de cinco anos são $26,7 \%$ dos respondentes.

Com relação à renda familiar, como já esperado para esse tipo de tecnologia, $100 \%$ das famílias tem uma renda superior a três salários-mínimos. Observando a escolaridade dessa população respondente, verifica-se que $58,6 \%$ têm ensino superior e que $41,4 \%$ são pós-graduados. Não se encontrou, nessa população pesquisada, nenhum caso de escolaridade com apenas ensino fundamental ou médio. Ainda observando aspectos socioeconômicos, com relação ao número de pessoas moradoras em cada habitação, $0 \%$ tem apenas um habitante, $6,6 \%$ tem duas pessoas em cada habitação, $20,0 \%$ tem três habitantes, $46,7 \%$ do universo pesquisado contemplam quatro moradores em cada habitação e $26,7 \%$ com cinco moradores em cada casa. Não se constatou casos de seis ou mais moradores em uma única habitação. Finalizando a caracterização socioeconômica, conforme ilustra a Figura 9, há uma grande distribuição de tipos de tipos de ocupação do chefe dessas famílias, especialmente por se tratar de área urbana. Destaques especiais para $33,3 \%$ que figuraram como empresários, $13,3 \%$ de médicos e $10,0 \%$ de engenheiros civis. 
Tabela 2: Caracterização socioeconômica da população entrevistada para microgeração fotovoltaica

\begin{tabular}{|c|c|c|c|}
\hline CATEGORIA & SUBCATEGORIA & $\begin{array}{c}\text { FREQ. } \\
\text { ABSOLUTA }\end{array}$ & $\%$ \\
\hline 1) Gênero & $\begin{array}{c}\text { Masculino } \\
\text { Feminino } \\
\text { Total }\end{array}$ & $\begin{array}{c}26 \\
4 \\
30\end{array}$ & $\begin{array}{c}86,7 \% \\
13,3 \% \\
\mathbf{1 0 0 , 0 0 \%}\end{array}$ \\
\hline 2) Tempo de Moradia & $\begin{array}{c}\text { até } 1 \text { ano } \\
\text { de } 1 \text { a } 2 \text { anos } \\
\text { de } 2 \text { a } 5 \text { anos } \\
\text { mais que } 5 \text { anos } \\
\text { Total }\end{array}$ & $\begin{array}{c}9 \\
4 \\
9 \\
8 \\
30\end{array}$ & $\begin{array}{c}30,0 \% \\
13,3 \% \\
30,0 \% \\
26,7 \% \\
100,0 \%\end{array}$ \\
\hline 3) Renda Familiar & $\begin{array}{c}\text { até } 1 \text { S.M. } \\
1 \text { a } 3 \text { S.M. } \\
\text { Mais de } 3 \text { S.M. } \\
\text { Total }\end{array}$ & $\begin{array}{c}0 \\
0 \\
30 \\
30\end{array}$ & $\begin{array}{c}0,0 \% \\
0,0 \% \\
100,0 \% \\
100,0 \%\end{array}$ \\
\hline 4) Escolaridade & $\begin{array}{c}\text { até 4a. Série } \\
\text { Ensino Fundamental } \\
\text { Ensino Médio } \\
\text { 3o. Grau } \\
\text { Pós graduado } \\
\text { Total }\end{array}$ & $\begin{array}{c}0 \\
0 \\
0 \\
17 \\
12 \\
29\end{array}$ & $\begin{array}{c}0,00 \% \\
0,00 \% \\
0,00 \% \\
58,6 \% \\
41,4 \% \\
100,0 \%\end{array}$ \\
\hline 5) $N^{\circ}$. pessoas na hab. & $\begin{array}{c}\text { Uma } \\
\text { Duas } \\
\text { Três } \\
\text { Quatro } \\
\text { Cinco } \\
\text { Mais que cinco } \\
\text { Total }\end{array}$ & $\begin{array}{c}0 \\
2 \\
6 \\
14 \\
8 \\
0 \\
30\end{array}$ & $\begin{array}{c}0,00 \% \\
6,6 \% \\
20,0 \% \\
46,7 \% \\
26,7 \% \\
0,00 \% \\
100,0 \%\end{array}$ \\
\hline
\end{tabular}

Fonte: Resultados da Pesquisa 


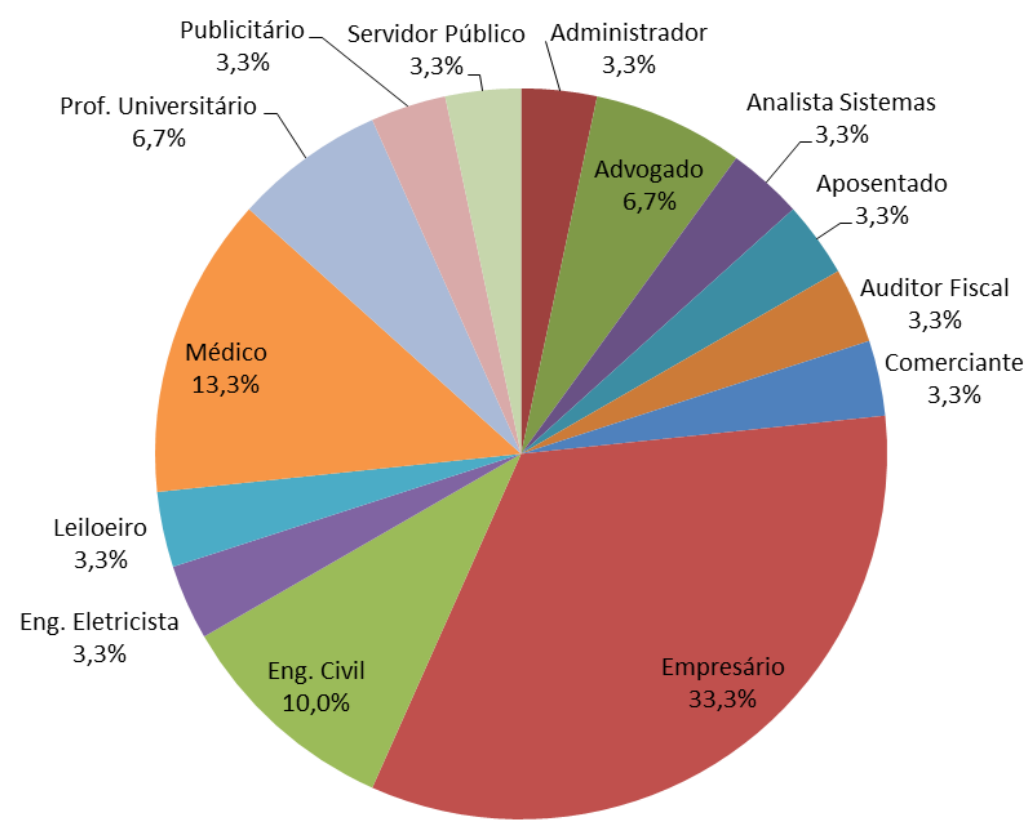

Figura 9: Ocupação do chefe da família - microgeração fotovoltaica.

Fonte: Resultados da Pesquisa.

Quanto à adaptação ao uso do microgerador de energia solar fotovoltaica, como se trata de aspectos de incorporação de tecnologia, foi proposto verificar se os respondentes receberam treinamento para o uso do equipamento. Em $100 \%$ dos casos, as respostas foram que sim, feito pela empresa instaladora. Também, em $100 \%$ dos casos os moradores responderam que o equipamento funciona bem. Ainda, foi perguntado aos respondentes da pesquisa há quanto tempo está instalado o microgerador de energia solar fotovoltaica em suas residências. Conforme ilustrado na Figura 10, apresenta-se um gráfico de frequência estatística do tempo de instalação do sistema. A média de tempo de instalação é de 8,6 meses.

Tempo de instalação do sistema

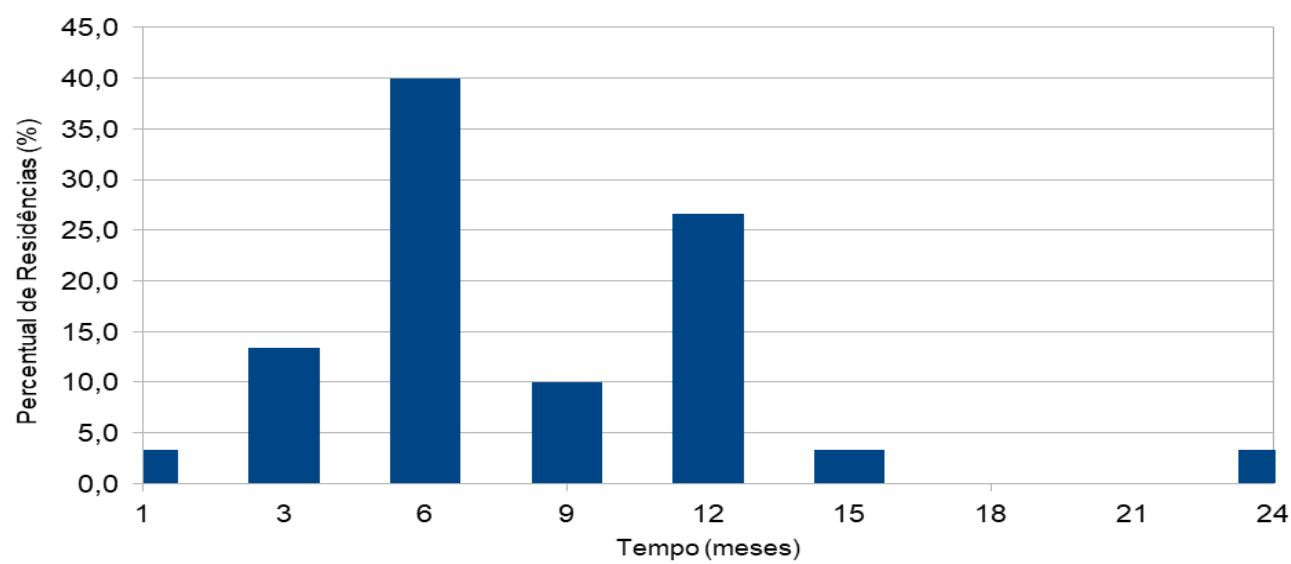

Figura 10: Frequência estatística do tempo de instalação por residência - microgeração fotovoltaica. Fonte: Resultados da Pesquisa. 
Por fim, foi perguntado ao respondente qual sua motivação para a instalação do microgerador, e $60,0 \%$ responderam que foi pela economia financeira, enquanto $36,7 \%$ responderam que foi a sustentabilidade ambiental e $3,3 \%$ responderam que estão fazendo um teste com a tecnologia. Percebe-se, nesta pesquisa, que os empresários escolheram a instalação do sistema, principalmente, por motivos financeiros, enxergando na tecnologia uma possibilidade de investimento, economia e retorno financeiro. Enquanto, outras profissões, médicos e engenheiros, por exemplo, citam a questão da sustentabilidade como principal motivo para a instalação.

Da mesma forma que no estudo de caso anterior, no último tópico da pesquisa de campo a intenção é traçar considerações sobre a percepção ambiental da população pesquisada que instalou microgeradores de energia solar fotovoltaica. Quando perguntado se consideram o microgerador importante para o meio ambiente, $100 \%$ responderam que sim, fazendo uma correlação entre economia de energia e preservação ambiental. Neste público pesquisado, verifica-se uma percepção ambiental bastante apurada em relação às suas responsabilidades enquanto integrantes do meio ambiente. Como já dito anteriormente, $36,7 \%$ responderam que foi a sustentabilidade ambiental a principal motivação para instalação do sistema. Para a pergunta: "Para você, qual a importância do Meio Ambiente?", os resultados encontrados foram: Tudo que envolve a natureza - 16,7\%, tudo que representa a vida, 40,0\%, tudo relacionado ao futuro $20 \%$, meio ao qual estamos inseridos $13,3 \%$ e outros 10,0\%, conforme ilustrado na Figura 11.

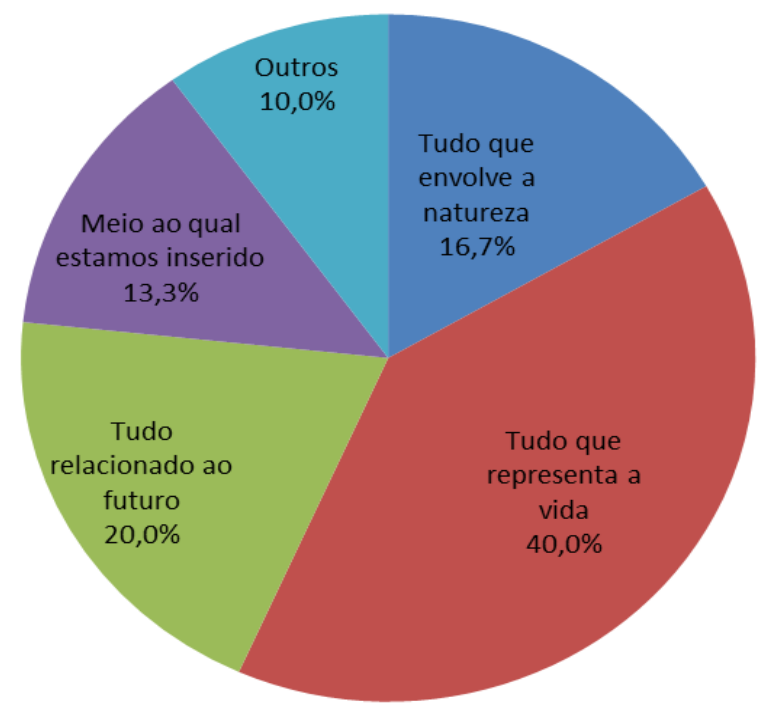

Figura 11: Distribuição das respostas sobre qual a importância do meio ambiente - FV.

Fonte: Resultados da Pesquisa

Adicionalmente quando indagados onde aprendeu a importância do meio ambiente, a distribuição das respostas foi conforme ilustrado na Figura 12. Observa-se que $50,0 \%$ disseram que aprenderam esses conceitos no ambiente acadêmico, 13,3\% responderam que aprenderam devido à leitura a respeito. 
Também, 13,3\% apontaram que foi devido à cultura geral (vários fatores), $10,0 \%$ explicaram que foi nos meios de comunicação.

Depois, em uma questão aberta, foi perguntado o que a pessoa gostaria de acrescentar, ainda, sobre o microgerador solar fazendo parte do cotidiano de sua família. As respostas foram ilustradas na Figura 13: tudo com cuidar do meio ambiente $-20,0 \%$, muito bom (apenas) - 10,0\%, tudo com economia de energia - $16,7 \%$, tudo com sustentabilidade - $26,7 \%$, tudo com diminuir o impacto ambiental $-6,7 \%$, nada $-16,7 \%$, outras respostas diversas $-3,3 \%$.

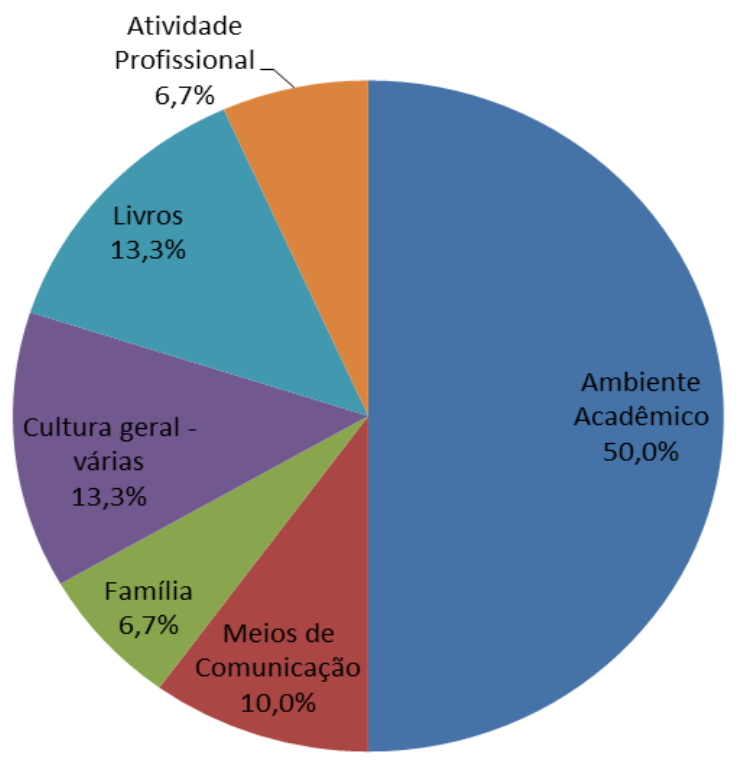

Figura 12: Distribuição das respostas sobre onde aprendeu a importância do Meio Ambiente microgeração fotovoltaica. Fonte: Resultados da Pesquisa

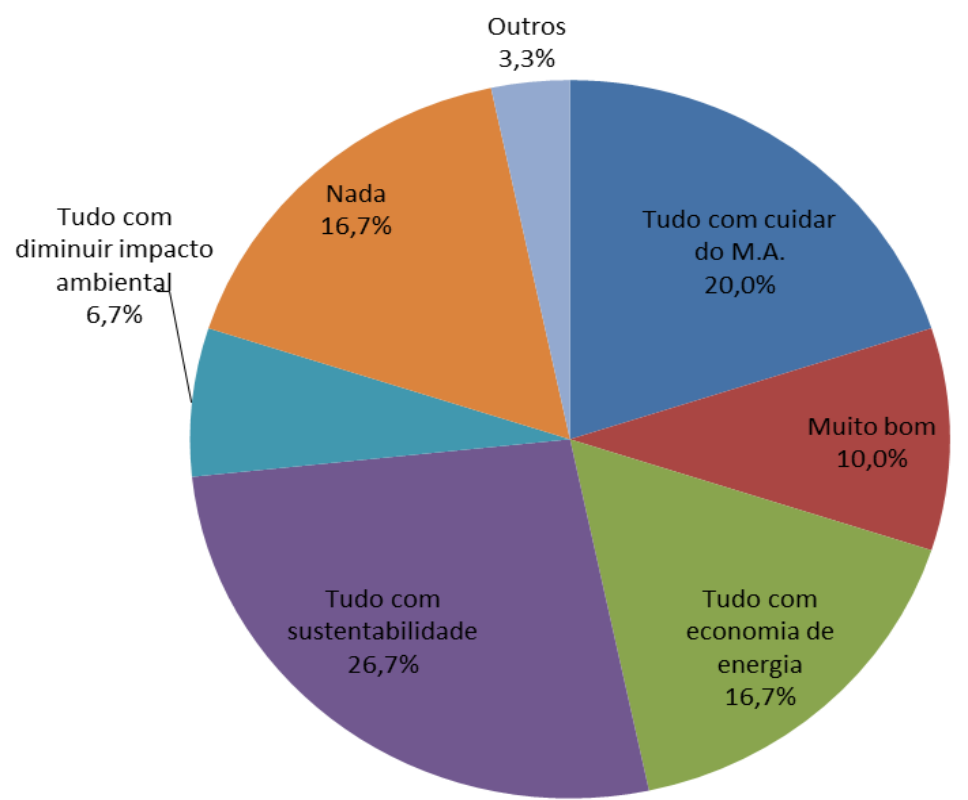

Figura 13: Distribuição das respostas para o que gostaria de acrescentar sobre o microgerador solar. Fonte: Resultados da Pesquisa 
Muitos citaram a importância de uma política pública para as energias renováveis. Tanto no sentido do incentivo, quanto linhas de financiamento adequadas para que todos tenham acesso à tecnologia. Por fim foi questionado se o conhecimento que eles têm sobre meio ambiente contribuiu para o entendimento e a decisão de uso do microgerador solar fotovoltaico e $100 \%$ dos respondentes indicaram que sim. Inclusive, muitos citaram que já possuiam aquecimento solar anteriormente instalado em sua residência e que isso contribuiu para sua decisão de instalar o microgerador.

\section{Conclusões}

Esta pesquisa objetivou investigar as relações entre o aproveitamento da energia solar e educação ambiental verificando a percepção ambiental despertada na população pela utilização desses sistemas. Essa avaliação foi desenvolvida na cidade de Curitiba e compreendeu uma análise pósocupacional, por meio de questionários aplicados e de observações in loco.

A entrevista semiestruturada foi utilizada como técnica de pesquisa. Para efetivação das entrevistas foram construídos dois instrumentos de pesquisa de campo. Um a ser aplicado nos usuários de sistemas de aquecimento solar e outro em usuários de sistemas de geração de energia solar fotovoltaica.

No estudo de caso para aquecimento solar foi escolhido o conjunto habitacional denominado de Moradias Nilo, estabelecida na cidade de Curitiba / PR. Nesta localidade foram implantadas 66 unidades habitacionais do Programa Minha Casa Minha Vida em parceria com a COHAB

$\mathrm{Na}$ avaliação da percepção ambiental dessa população, 52,5\% consideram o aquecimento solar importante para o meio ambiente, embora alguns não saibam explicar. Para eles, a importância do Meio Ambiente envolve conceitos como a natureza $20,0 \%$, a vida, $27,5 \%$, e futuro $25,0 \%$. Observou-se que $32,5 \%$ disseram que aprenderam esses conceitos na escola, $30,0 \%$ responderam que aprenderam nos meios de comunicação, especialmente TV, e $22,5 \%$ indicaram que foram motivados pelas empresas onde trabalharam. A pesquisa revelou ainda, que existe um grande déficit, espaço e oportunidade para se trabalhar a educação ambiental neste tipo de população.

O estudo de caso para microgeração de energia solar foltovoltaica foi realizado na cidade de Curitiba / PR, onde foram instalados sistemas dessa tecnologia por opção do proprietário do imóvel. Foi aplicado um questionário em 30 residências. Da mesma forma que no estudo de caso anterior, no primeiro tópico foram coletadas informações acerca das características sócioeconômicas das famílias residentes.

Com relação à renda familiar, para esse tipo de tecnologia, 100\% das 
escolaridade dessa população respondente, verifica-se que $58,6 \%$ têm ensino superior e que $41,4 \%$ são pós-graduados. E quanto à motivação para a instalação do microgerador $60,0 \%$ responderam que foi pela economia financeira, $36,7 \%$ disseram que foi a sustentabilidade ambiental e $3,3 \%$ responderam que estão fazendo um teste com a tecnologia.

Verificou-se uma percepção ambiental bastante apurada nesta população, pelas conversas nas entrevistas. Como resultado, $50 \%$ disseram que aprenderam esses conceitos no ambiente acadêmico, $13,3 \%$ devido à leitura à respeito, 13,3\% apontaram à cultura geral e 10,0\% atribuíram aos meios de comunicação. Para eles a educação geral e especificamente a educação ambiental é fator primordial em a busca da sustentabilidade.

\section{Agradecimentos}

À Fundação Araucária, pelo apoio financeiro à pesquisa; à Universidade Federal do Paraná, por tornar possível o doutoramento do autor.

\section{Referências}

ACHÃO, C.C.L. Análise da Estrutura de Consumo de Energia no Setor Residencial Brasileiro. 2003. Tese (Doutorado em Planejamento Energético) COPPE/Universidade Federal do Rio de Janeiro, Rio de Janeiro, RJ, 2003.

ACKERMAN, T; GÖRAN, A; SÖDER, L. Distributed generation: a definition. Electric Power Systems Research, v. 57, n. 3, 2001. DOI: 10.1016/S03787796(01)00101-8.

AGÊNCIA NACIONAL DE ENERGIA ELÉTRICA (ANEEL). Atlas de Energia Elétrica do Brasil. Brasília, 2005.

AGÊNCIA NACIONAL DE PETRÓLEO (ANP). Boletim de Recursos e Reservas de Petróleo e Gás Natural 2016. Brasília, 2017.

ASCERALD, H.. Ambientalização das Lutas Sociais: o caso do movimento por justiça ambiental. São Paulo: Estudos Avançados, 2010.

BARDIN, L. Análise de Conteúdo. Lisboa: Edições 70, LDA, 2009.

BRANCO, S. M. Energia e meio ambiente. São Paulo: Moderna, 2002.

BREHM, M. A. Geração de energia elétrica fotovoltaica distribuída por pequenos consumidores domésticos no Paraná: potencialidades e aspectos sócio-ambientais. Dissertação (Mestrado em Desenvolvimento e Meio Ambiente), Universidade Federal do Paraná, Curitiba, 2014.

BRITO M. C.; VALLÊRA, A. Meio século de história fotovoltaico. Lisboa: Departamento de Física e Centro de Física da Matéria Condensada (CFMC), 2006. 
COLLE, S. et al. Impacto da energia solar sobre o pico de demanda de energia de chuveiros elétricos de famílias de baixa renda no Brasil. In: XII Congrese Ibérico, 12, 2004, Vigo; Congreso Íbero Americano de Energía Solar, 7, 2004, Vigo. Anais... Vigo: Editora M. Vazquez; J. F. Seara, 2004.

COTTRELL, F. Energy and Society: The Relation Between Energy, Social Change, and Economic Development. New York: McGraw Hill, 1955.

DEMO, Pedro. Metodologia científica em Ciências Sociais. 3. Ed. São Paulo: Atlas, 1995.

DEPARTAMENTO NACIONAL DE AQUECIMENTO SOLAR (DASOL/ABRAVA). Relatório de Pesquisa Produção de Coletores Solares para Aquecimento de Água e Reservatórios Térmicos no Brasil - Ano de 2015. São Paulo: DASOL/ABRAVA, 2016.

DORON, R.; PAROT, F. Dicionário de Psicologia. Lisboa: Climepsi Editores, 2001.

DUFFIE, J. A.; BECKMAN, W. A. Solar engineering of thermal processes. 4. ed. New York: John Wiley \& Sons, Inc., 2013.

EMPRESA DE PESQUISA ENERGÉTICA (EPE). Balanço Energético Nacional 2016: Ano base 2015, Rio de Janeiro: EPE. 2016.

ENVIRONMENTAL POLICY INTEGRATION IN EUROPE (EEA). State of play and an evaluation framework. Copenhagen: [s.n.], 2005. Disponível em: $<$ http://www.eea.europa.eu/publications/technical report $20052>$.

FAGGIONATO, S. Percepção ambiental. Material e textos. 2011. Disponível em: <http://educar.sc.usp.br>. Acesso em: 09 jan. 2018.

FANTINELLI, J. T. Análise da evolução de ações na difusão do aquecimento solar de água para habitações populares Estudo de caso em Contagem - MG. Tese (Doutorado em Engenharia Mecânica) - Universidade Estadual de Campinas (UNICAMP), Campinas, 2006.

FOLADORI, G. O Capitalismo e a crise ambiental. Revista Raízes, v. 18, n. 19, maio 1999.

FRAIDENRAICH, N. Tecnologia solar no Brasil. Os próximos 20 anos. Disponível em: $<$ http://www.feagri.unicamp.br/energia/energia2002/jdownloads/pdf/papers/pap er Fraidenraich.pdf >. Acesso em: 17 jul. 2017.

FURTADO, C. Em busca de novo modelo. São Paulo: Paz e Terra, 2002.

GIL, A. C. Métodos e técnicas de pesquisa social. São Paulo: Atlas, 1999.

KNECHTEL, M. R.; FLORIANI, D. Educação ambiental: epistemologia e metodologias. Curitiba: Gráfica Vicentina, 2003.

LEFF, E. Saber ambiental: sustentabilidad, racionalidad, complejidad, poder. México: Siglo XXI Editores/PNUMA, 1998. 
LEFF, E. A complexidade ambiental. São Paulo: Cortez Ed., 2003.

MORIN, E. Introducción al pensamiento complejo. 3. ed. Barcelona: Gedisa, 1997.

NASPOLINI, H. F.; MILITÃO, H. S. G.; RÜTER, R. The role and benefits of solar water heating in the energy demands of low-income dwellings in Brazil. Energy Conversion and Management. V. 51, n. 12, dez. 2010.

O'CONNOR, J. ¿Es posible el Capitalismo sostenible? In: ALIMONDA, H. (Org.). Ecología política, naturaleza, sociedad y utopía. Buenos Aires: CLACSO, 2002.

OKAMOTO, J. Percepção ambiental e comportamento. São Paulo: Plêiade, 1996.

PEREIRA, E.B et al. Atlas brasileiro de energia solar. Swera, São José dos Campos, 2006.

PEREIRA, E. B. et al. Atlas brasileiro de energia solar., São José dos Campos: INPE, 2017.

PEREIRA, E. M. D. et al. Energia Solar Térmica. In: TOLMASQUIM, M. T. (Org). Fontes renováveis de energia no Brasil. Rio de Janeiro: Interciência, 2003.

ROKEMBACH. H. L. Aspectos sociais relacionados à difusão de sistemas fotovoltaicos conectados à rede em residências na cidade de Curitiba. Dissertação (Mestrado) - Universidade Federal do Paraná, Curitiba, 2016.

ROBBINS, S. Comportamiento organizacional, México: Prentice-Hall, 1999.

RÜTHER, R. Edifícios solares fotovoltaicos: o potencial da geração solar fotovoltaica integrada a edificações urbanas e interligada á rede elétrica pública no Brasil. Florianópolis: LABSOLAR, 2004.

WACHSMANN, Ulrike. Mudanças no consumo de energia e nas emissões associadas de CO2 no Brasil entre 1970 e 1996: Uma análise de decomposição estrutural. 2005. Dissertação (Doutorado em Planejamento Energético). Universidade Federal do Rio de Janeiro, Rio de Janeiro, 2005.

WHITE, L. A. The Evolution of Culture. New York :McGraw Hill, 1959.

WILD, M. et al. A New Diagram of the Global Energy Balance. , New York: American Institute of Physics, 2013.

YIN, R. K. Case study research: design and methods. New York: Sage Publications, 1990. 